\title{
The Implementation of Management Information System of Planning School Infrastructure Development Based on Priority Scale (SIMPPIS) to Improve Students' Achievement
}

\author{
Sucipto $^{1}$, Tri Joko Raharjo ${ }^{2}$, S. Martono ${ }^{3}$, DYP Sugiharto ${ }^{4}$, Virgiawan A.K ${ }^{5}$. \\ 1,2,3,4,5 Graduate School, Universitas Negeri Semarang, Indonesia \\ ${ }^{1}$ Coresponding email: sucipto@mail.unnes.ac.id
}

\begin{abstract}
Successful development is the regional government's objective. To achieve the objective, the government needs supporting sectors. One of them is education. By numerous students, school needs components supporting school infrastructure. By the fund limitation, the development of school infrastructure, however, cannot be conducted simultaneously. The development is based on the priority scale depending on the needs. The approach used in the study was qualitative. The scientific study emphasized on the scientific character of the data source. The study described the importance of the SIMPPIS use. Location or object of the study was state junior high school in Salatiga. Data of the study were collected through interview with principals and teachers in the junior high school in Salatiga. The document study was conducted by book analysis, meeting agenda, and archives. The availability of the entire infrastructures was said as fulfilled well and using proper planning could fasten development process, so the students could study comfortably, focus, and developed well by the complete supporting infrastructure. By SIMPPIS the planning of school infrastructure development could be accommodated and proper as needed by the school and could be proceed quickly.
\end{abstract}

Keywords: SIM, Infrastructure, Priority scale, Achievement

\section{Introduction}

Successful development is the regional government's goal. To achieve the goal, the government needs supporting sectors. One of them is education. Education is one of supporting keys for a region economic growth (Pal, 2010. ). Consequently, the availability of education infrastructure must result in reliable service in a region by following the development of either internal or external system which are developing continuously, and it must be responded comprehensively to provide best education service solution. By the numerous numbers of students, school needs component supporting infrastructure. Due to limited fund, developing school's infrastructure cannot be conducted simultaneously. The development should be based on the priority scale as needed. The infrastructure development for school in Indonesia in general and especially in Salatiga did not achieve targets because it was not suitable with school needs. It was based on grant from government or the deviant policy. Besides, there were many schools (especially primary education) having physical infrastructure under minimum service standard and the limitation of fund resulting bad infrastructure development.

The regional government had principle tools used in proposing school infrastructure development. The proposal mechanism was still done manually so that in the government could not see comprehensively emerged priority of school infrastructure development proposal. It tended to deviant policy on the policy maker level. The limited budget was the most important thing need to be considered because according to financial administration broadly, the policy of providing and using money to realize working organization activity including planning, organizing responsibility and financial monitoring activities. System is a range of elements interdependently to achieve certain goal. System must include organization, feedback, integration and vision. It, therefore, can be concluded that system is a range of element interdependently to achieve goal in regular process supporting bigger system and has dependency to achieve the vision (Gelinas, 2012).

Decision supporting system is interactive computer base assisting the decision makers to use data and various models to solve unstructured issues (E., 2005) states that decision supporting system integrates intellectual resource of individual with computer capability to improve decision quality. SPK is a supporting system-computer base for the management decision maker controlling unstructured issues. The goals refer to three basic principles of decision supporting 
system (Oetomo, 2002.) namely (1) structure of issue, for structured issue, the solution could be found by using suitable formulas, and for unstructured issue, the solution could not be computerized. Meanwhile, the decision supporting system is developed, especially to solve the semi-structured issue; (2) the support for decision supporting system is not aimed to turn over the manager, due to the computer in structured division, and the manager is in unstructured division to assess and analyse the issue. Manager and computer work together as a team of semi-structured problem solver; (3) decision effectiveness, the main goal of decision supporting system is not to cut time of decision making, otherwise the decision made is better.

The information system is a collection of components that collect, process, store, and provide output of any information required in business processes and applications used through software, databases and even the associated manual processes(Satzinger, 2010). Information Systems an element or component of people, procedures, databases and interrelated tools to process, store and produce information to achieve a goal.(Stair, 2012).

Infrastructure is defined as physical system providing transportation, water, drainage, building and other public facilities, needed to fulfil human basic needs either social or economic needs (Grigg, 1998). The definition refers to infrastructure as a system, in which infrastructure in a system is divisions of facility (network) included each other. Infrastructure in a system supporting social and economic system have related to the environment. The availability of the infrastructure has impact on social and economic system in the society. Infrastructure, therefore, need to be understood as bases to take policy (Kodoatie, 2003). Education service in education institution specifically or service in organization in general can achieve the target and faster when it uses information technology facilities. Use of information technology in an organization may cause change on the organization structure and working process (Turban, 2004). The implementation of information technology brings fundamental change on the organization including structure of reporting, supervision, working substance, and working division. The use of information technology can improve productivity of the manager, improve supervision, and decrease the number of manager on medium level, so the organization structure is flat (flatter organizational hierarchy) (E., 2005). The organization board which is horizontal, more decentralist, more coordinative, narrower scope of work, and bigger professional staff ratio.

\section{Method}

The approach used in the study was qualitative, in which the study did not use counting process. It is a scientific study emphasizing scientific characteristic of the data source. This study described the importance of SIMPPIS use. The object of the study was state junior high school in Salatiga city. Data of the study were collected through interview toward headmasters and teachers of the state junior high school in Salatiga. The study of document was carried out by studying book, note and archive analysis.

\section{Results and Discussion}

The planning model of infrastructure development of school in Salatiga is conducted manually in form of proposal proposed to education board manually.

The proposal proposed is not based on the needs analysis; otherwise it waits information from the education board about development budget available. It often occurs that the infrastructure given is not suitable with the needs of the schools, so that it is useless and the most important one is not fulfilled. The data collected is unorganized well, it is often lost when it is collected to the education board or incomplete. They often make list repeatedly which is time consuming. It needs more time in planning process of infrastructure development.

Planning model design of management information system of infrastructure development for infrastructure-based school in Salatiga is shown as follow: planning stage uses management information system of school infrastructure planning based priority focusing on the identifying condition and needs of school after they had composed program proposal which is suitable with the agreement between headmaster, teacher board, and school committee through SIMPPIS. Holding training for special officer or school operator to input data in SIMPPIS. Process of proposing proposal is replaced by process of input data of school condition and program 
proposed to develop infrastructure to SIMPPIS which automatically turns to be proposal of school infrastructure development planning.

Organizing. The use of management information system for planning school infrastructure priority based is communicating needs of infrastructure development through committee meeting, and then the school appoints teacher board collecting complains from school holder concerning school infrastructure development needs. They, then, communicate it to team of building and developing school or to infrastructure officer. The presentation of the team of building and developing school divides duty for the school committee and teacher board in process of infrastructure development proposal.

Implementing. The use of management information system in planning school infrastructure development priority base in implementing phase is process of sending proposal from school to SIMPIS; inputting data in accordance to items in the system. After that, it waits validating process or follow up from education board. Process of delivering proposal is suitable with the initial strategic planning of learning completed by additional statement whether there is sudden needs. The process of data input is done simultaneously and timely by education board. The final execution of the infrastructure development planning proposal is conducted by special team that is K-Prove, the mixture of regional development board and education board.

Monitoring and evaluation. The use of management information system for planning school infrastructure development priority base in monitoring and evaluation phase is done by periodical monitoring by inspectorate through SIMPIS involving law officer which also uses SIMPIS.

The use of SIMPPIS enable users to: (1) improve data accessible presented accurately and timely; (2) ensure the availability of quality and skill in using information system critically; (3) developing effective planning process; (4) identifying development planning needs; (5) determining investment directed to information system; (6) anticipating and understanding economic consequences of up to date information system and technology. Based on the interview result to the headmaster and teacher, it shows that the use of SIMPPIS influences significantly the students' achievement. The complete school facilities improve learning process. School infrastructure is supporting element in teaching learning process. The inexistence of enough facility influences students' attitude. The provision of good infrastructure supporting students' development in suitable condition highly influence the achievements.

Good building facility may create comfort atmosphere so that the students concentrate in their learning process. The availability of learning media adapting the developing world may improve students' creativity, so their knowledge develops well. Good library in terms of room and books helps students to develop and get additional knowledge. Building and equipment of laboratory makes students having experiments on new thing resulting newer findings and enforce students to have critical thinking and be creative. The provision of very good technology facility helps students to get updated technology. The students can expose their competence in IT. The availability of the infrastructure can be fulfilled well through good planning process enforcing building process so that students can study comfortably, focus and, develop well supported by completed infrastructure. By SIMPPIS, entire school infrastructure development planning can be accommodated and proper based on the school needs and proceeded quickly. (Spaull, 2013a)had conducted research about school infrastructure in South Africa showing that beside for teacher, good supporting infrastructure in education influences the quality of school output. Therefore, every year or semester school build school infrastructure to have updated supporting infrastructure and to fulfill the infrastructure they do not have before. The educational infrastructure is estimated at 10 million classrooms and 100 billion dollars to build school infrastructure worldwide for the realization of the Millennium Development Goals (Gershberg (2014)

\section{Conclusion}

The use of information technology can improve productivity of the manager, improve supervision, and decrease the number of managers on medium level, so the organization structure is flat (flatter organizational hierarchy).

The organization board which is horizontal, more decentralist, more 
coordinative, narrower scope of work, and bigger professional staff ratio.

The availability of the infrastructure can be fulfilled well and through good planning process enforcing building process so that students can study comfortably, focus and develop well supported by completed infrastructure. Through SIMPPIS, the entire school infrastructures development planning can be accommodated properly based on the school needs and proceeded quickly

\section{References}

E., T. (2005). . Decision Support System and Intelligent Systems Yogyakarta: Andi Offset.

Gelinas, J. U., Dull, Richard B., Wheeler, Patrick R. . (2012. ). Accounting Information Systems. . South Western: Cengage Learning.

Gershberg, A. I. (2014). Educational Infrastructure, School Construction, \& Decentralization in Developing Countries. International Center for Public Policy Working(Key Issues for an Understudied Area).
Grigg, N. I. (1998). nfrastructure Engineering And Management. John Wiley and Sons.

Kodoatie, J. R. (2003 ). Pengantar Manajemen Infrastruktur. Yogyakarta Pustaka Pelajar.

Oetomo, B. S. D. ( 2002. ). Perencanaan dan Pengembangan Sistem Informasi. Yogyakarta: ANDI

Pal, S. ( 2010. ). Public infrastructure, location of private schools and primary school attainment in an emerging economy. . Economics of Education Review, 29(5), 783-794.

Satzinger, J., Burd. ( 2010). System Analisis and Design with the Unified Process. USA: Cengage Learning.

Spaull, N., 2013a. . (2013a). Poverty and privilege: primary school inequality in South Africa.. International Journal of Educational Development 33, 436447.

Stair, R. M., dan Reynolds, George W. (2012). Fundamentals of Information

Systems (With Access Code). USA: Cengage Learning. 